\title{
Non-missile penetrating brain injuries: cases registry in Sohag University Hospital
}

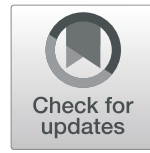

Ahmed Kamal Abdelhameid and Ahmed Saro* (B)

\begin{abstract}
Background: Non-missile penetrating brain injuries are rarely seen in the surgical practice and few international literatures' reported case reports or small case series, and it comprises a small percentage of head trauma cases. We reported a group of 18 cases of penetrating injuries with different tools and various mechanisms. We reported their epidemiological criteria, mechanism of trauma, complications, and their prognosis.
\end{abstract}

Aim: The purpose of this study is to report different patients' criteria and the method of trauma and the prognosis.

Patients and methods: A retrospective study was done in Trauma unit, Sohag University, between November 2012 and October 2014. Eighteen patients were reported with different mechanisms of trauma. All patients were clinically tested and subjected to CT brain. Cautious removal of the penetrating object with debridement of surrounding tissues was done. Patients were transferred to ICU for 48-72 h.

Results: Patients were subjected to operative intervention, and they were followed up for 3 years. Males were the predominant gender, 13 cases (72.2\%), and the young age was higher than the elderly. The Glasgow outcome score was 15 in 13 patients and was 4 in five patients. Transient epileptic fits occurred in six patients and controlled on antiepileptic drugs. Five patients had a neurological deficit in the form of hemiparesis or monoparesis.

Conclusion: Penetrating head injuries, although rare, are dangerous and should be cautiously managed and monitored in the ICU. The prognosis depends mainly on initial GCS and ventricular involvement, but in general, the prognosis is favorable.

Trial registration: IRB\#3747 Registered 27/08/2017

Keywords: Penetrating brain trauma (PBT), Traumatic brain injury (TBI), Computed tomography (CT), Vascular injury, Dural tear, Intensive care unit (ICU), Non-missile

\section{Introduction}

Traumatic brain injury (TBI) occurs when there is damage in the brain as a result of physical trauma. TBI may be caused by an open or penetrating head injury, where an object (usually sharp) pierces the skull and invades the brain tissue. TBI may be also caused by a closed head injury, in which the skull is intact and is not penetrated. TBI may cause major long-term disability of individuals surviving head injuries [1]. Cranial penetrating head injuries often result in severe brain and central nervous system (CNS) structure injuries [2]. Although penetrating head trauma is less common than closed head trauma, PBI is associated with worse prognosis and

\footnotetext{
* Correspondence: Ahmedsaro33@yahoo.com

Neurosurgery Department, Sohag Faculty of Medicine, Sohag University Hospital, Sohag, Egypt
}

\section{Springer Open}

(c) The Author(s). 2019 Open Access This article is distributed under the terms of the Creative Commons Attribution 4.0 International License (http://creativecommons.org/licenses/by/4.0/), which permits unrestricted use, distribution, and reproduction in any medium, provided you give appropriate credit to the original author(s) and the source, provide a link to the Creative Commons license, and indicate if changes were made. higher morbidity and mortality rates. Understanding the mechanisms of injury and aggressive medical management with rapid surgical intervention may lead to improved outcomes [3].

Traumatic brain injuries (TBI) caused by penetrating objects usually affect adolescents and young adult population, who are economically active, thus having a major socioeconomic impact. So, the economic burden includes not only the high cost with direct patient care, but also the potential loss of years of productive life [4].

Traumatic intracranial penetration of foreign non-missile object rarely occurs. Early mortality may be caused by hemorrhages, major vascular injury, or contusions, while epileptic seizures and infections are among the possible complications in later stages. Complete excision of the foreign object should be done for all patients and

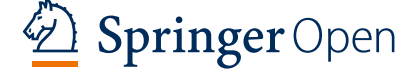



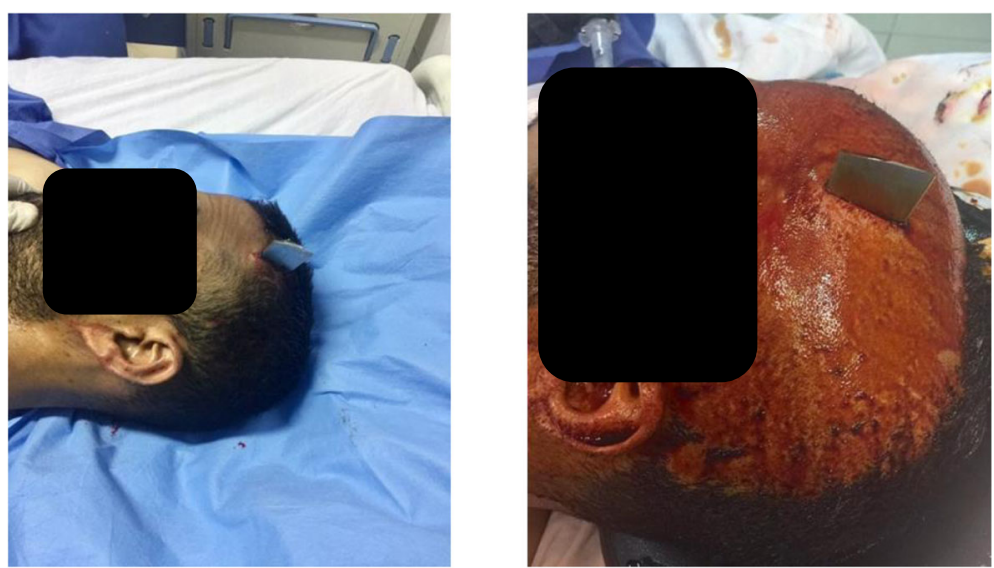

Fig. 1 A 33-year-old male patient came to the emergency department with penetrating head trauma with a knife. The knife blade was left in the skull and brain tissue, GCS was 15, and no neurological deficit. The patient is on the operating table before and after anesthesia

any dural and/or vascular injuries should be repaired during surgical treatment [5].

Neurological state, hemodynamic and respiratory status at hospital admission, type of penetrating object, pupil size, and reactivity, as well as the CT findings, all these factors will affect the prognosis so they should be evaluated carefully before the decision of the line of management. Intracranial infection, CSF leak and recurrent attacks of convulsions are the most common complications [6].

Our goal in this study to report cases with non-missile penetrating head injuries and evaluate the possible predictive factors in a series of 18 patients sustaining penetrating head injuries, admitted to our hospital over a period of 2 years, to be used as a guide for the surgical management.

\section{Patients and methods}

With the approval of the Ethics Committee, 18 patients treated by the Neurosurgery Department of Sohag University Hospital diagnosed with non-missile, penetrating brain injuries from November 2012 to October 2014. Data were collected and recorded including the following information: age, gender, Glasgow coma score (GCS) on admission, type of penetrating object, the affected brain region, modality of treatment, and outcome. All patients presented for complete neurological examination will have a full radiological study.

\section{Surgical procedure}

In a well-equipped operative theater and under general anesthesia with intra-arterial blood pressure monitoring,
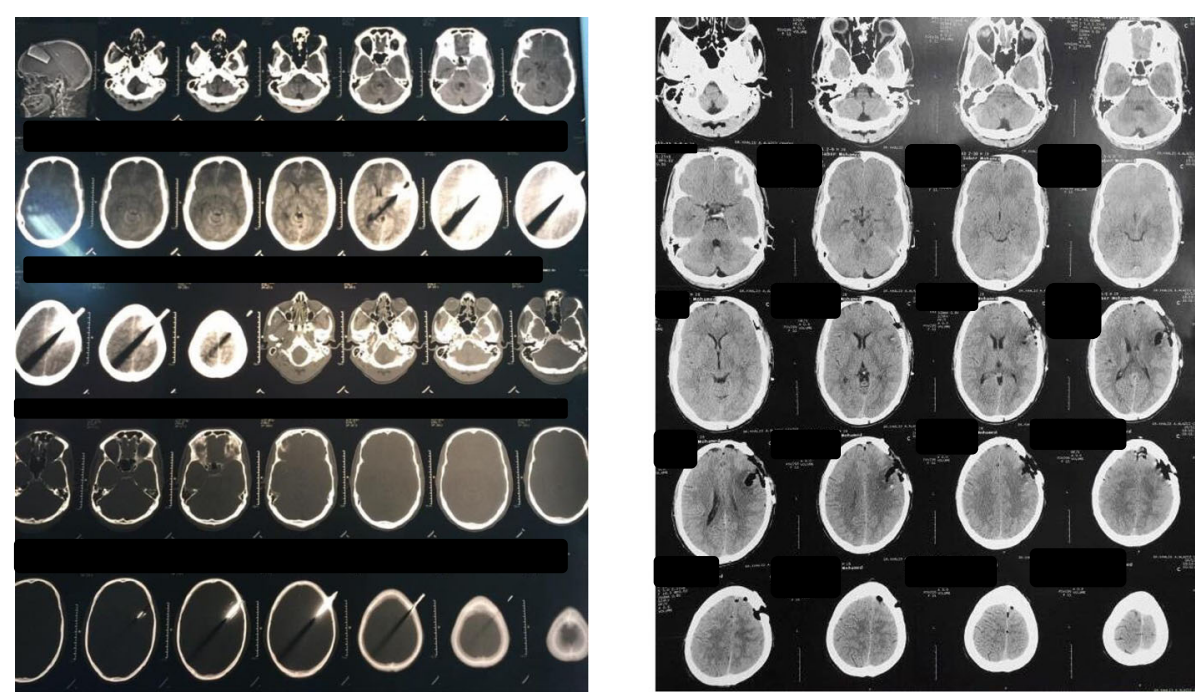

Fig. 2 Steps of blade extraction. CT scans of the same patient before and after blade extraction 


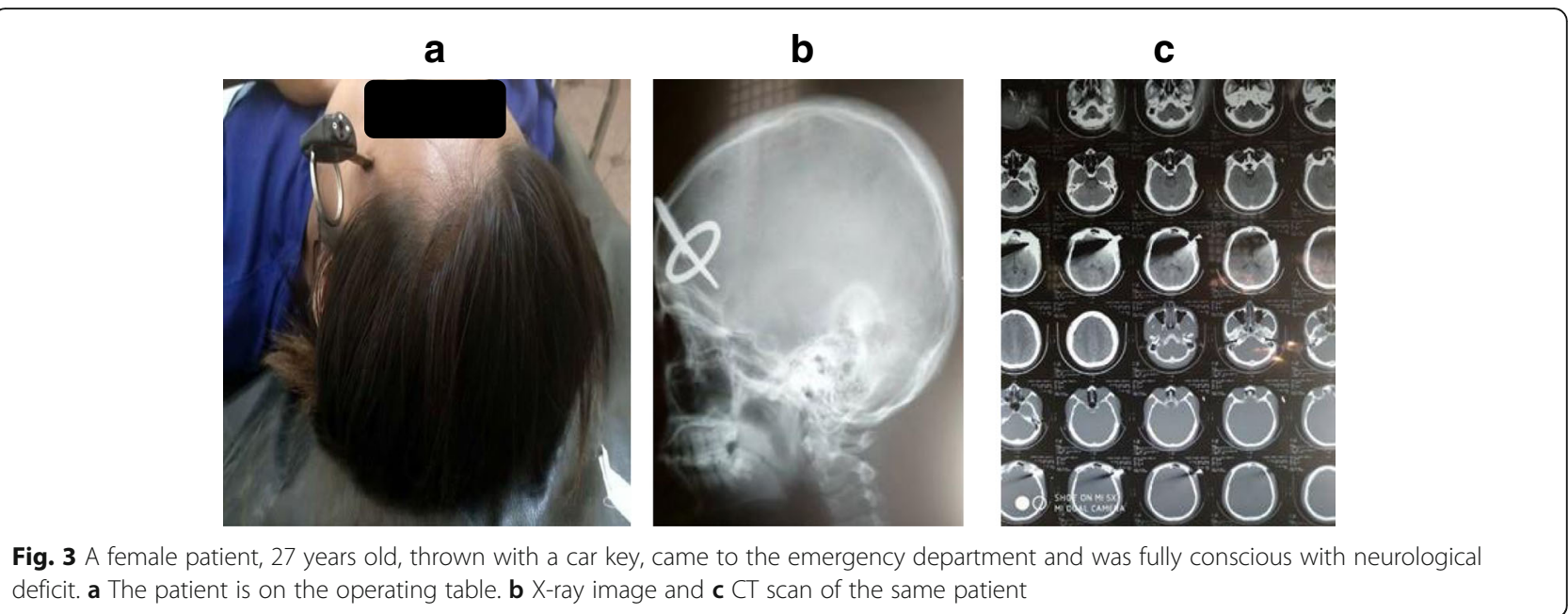

the patient is positioned according to the site of the penetrating object. The skin flap was elevated according to the site and the shape of the penetrating object. We performed a bone flap around the entry point of the penetrating object; these fragments were removed with debridement of necrotic brain tissue in five patients (Figs. 1, 2, 3, 4, 5, 6, 7, 8, and 9).

The dura should be explored well for any missing tear to avoid CSF leak and decrease the risk of infection. If there is a simple dural tear, the primary repair was done in two cases; however, in 11 cases with large gaps between the dural edges or a large tear extending to the base, duraplasty was performed using pericranium graft.

All our patients received the same standard medication protocol that includes a post-operative ICU admission with broad-spectrum antibiotics for 14 days post-operatively, together with a prophylactic anticonvulsant therapy, analgesic agents, and dehydrating measures if needed. CT scans for all patients were done immediately postoperative and 3 months later. Patients suffering from neurological impairment (five patients) following surgery underwent rehabilitation. All patients have to be followed up by periodic neurological examination and CT brain if needed every 3 months after discharge.

\section{Results}

More than two thirds (72.2\%) of our patients were males, and the remaining five cases $(27.8 \%)$ were females (Fig. 10); the mean patient age was 17.3 years range from 4 to 39 years. The commonest age group was the second

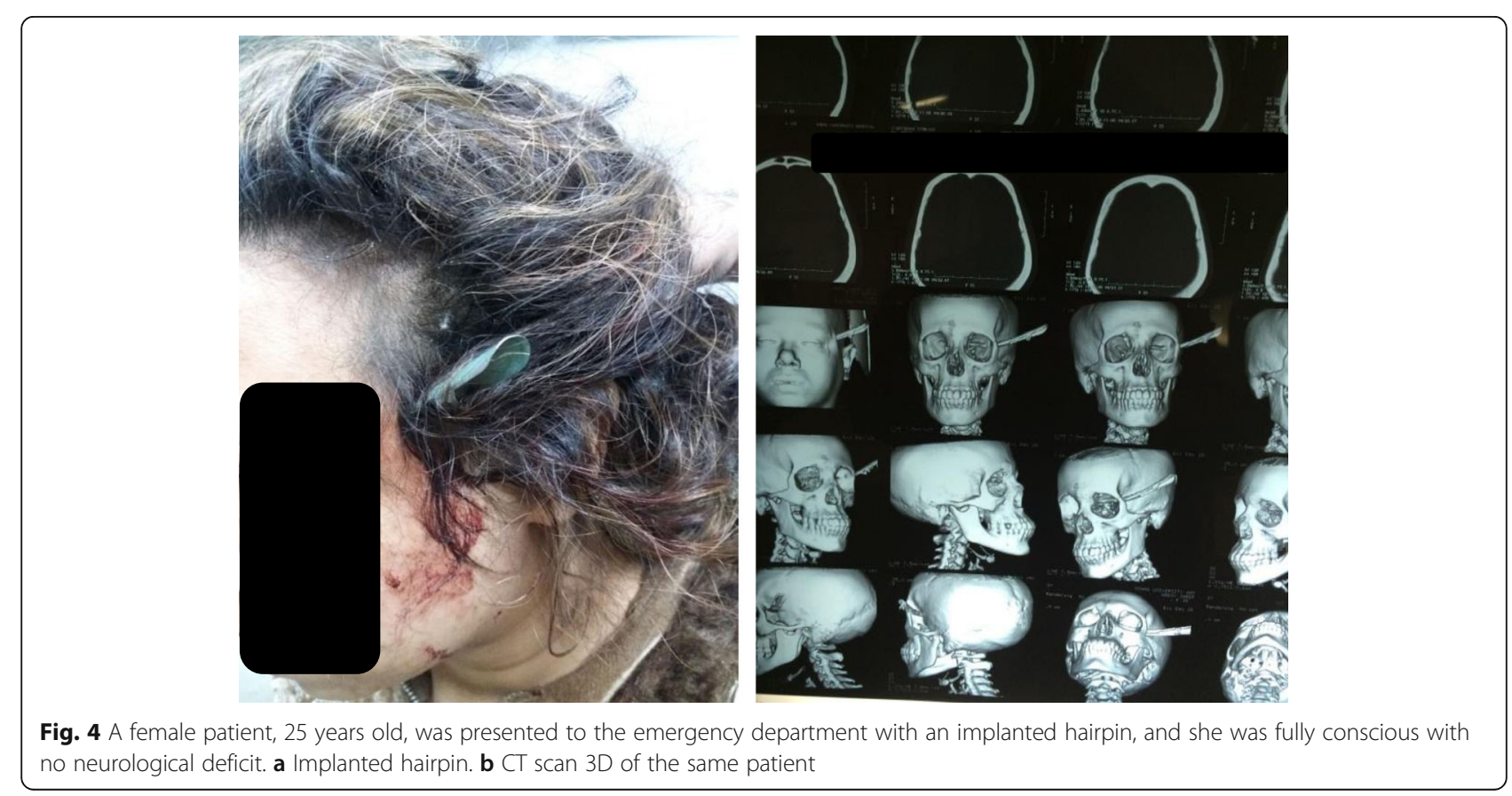



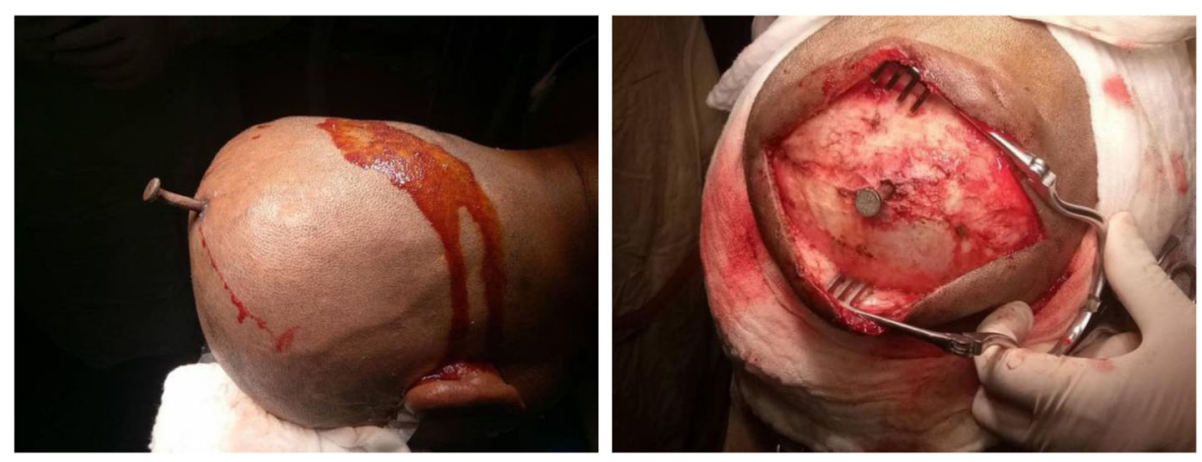

Fig. 5 A 23-year-old male patient was presented to the emergency department with an implanted nail from a nail-gun machine. He was fully conscious with no neurological deficit. Patient in the prone position after anesthesia with implanted nail shown. The nail after extraction with surrounded bone flab

decade (from 10-20 years) which is presented in nine patients while the least group was above 40 years by one patient (Fig. 11). Eleven patients were assaulted while seven patients injured accidentally.

Physical and radiological examination showed that the frontal lobe was the most common site of injury, found in 14 patients $(77.8 \%)$ followed by the temporal and parietal lobes (three patients), whereas fronto-parieto-occipital penetrating injury was seen in one patient $(5 \%)$ (Fig. 12). It was found that the frontal injury carries the best conscious level while patients with temporal or parietal injuries are associated with deterioration in the consciousness level or neurological deficits.

GCS scores at admission ranged from 3 to 8 in five patients and 8 to 15 in 13 patients, with a mean of $9.17 \pm$ 3.47. Thirteen patients in our series show a dural tear, and it was simply repaired in two cases while 11 cases repaired with a pericranium graft. Seven cases associated with underlying small intracerebral hematoma which had been evacuated. Ventricular injury was observed in three cases. Table 1 summarizes these data. Five patients were managed with debridement of necrotic tissues and retained parts in five patients while two cases were managed by primary closure. Debridement with duraplasty was performed in 11 patients.

The most common complication was infection, which was observed in six patients. The infection was either systemic infection in two cases or local wound infection in four cases, which need long-term broad-spectrum antibiotics regimen. Other surgical complications included posttraumatic fits in six patients, neurological deficit in the form of hemiparesis in three patients and monoparesis in two patients, intracranial hematomas in three patients, and hydrocephalus in one patient who needed insertion of a ventriculoperitoneal shunt as shown in Table 2.

Regarding the causative tool, knives were found in ten patients, while nails were the cause in four cases, then iron rod in two cases followed by a key and hair pin in one case for each (Table 3).

In this study, the mortality rate among the patients was $16.7 \%(n=3)$, and primary brain damage with intraventricular hemorrhage was the cause of death. The three dead patients were presented with GCS 4. The mean follow-up period for all patients was 20 months (range, 16 to 28). Patients with a neurological deficit
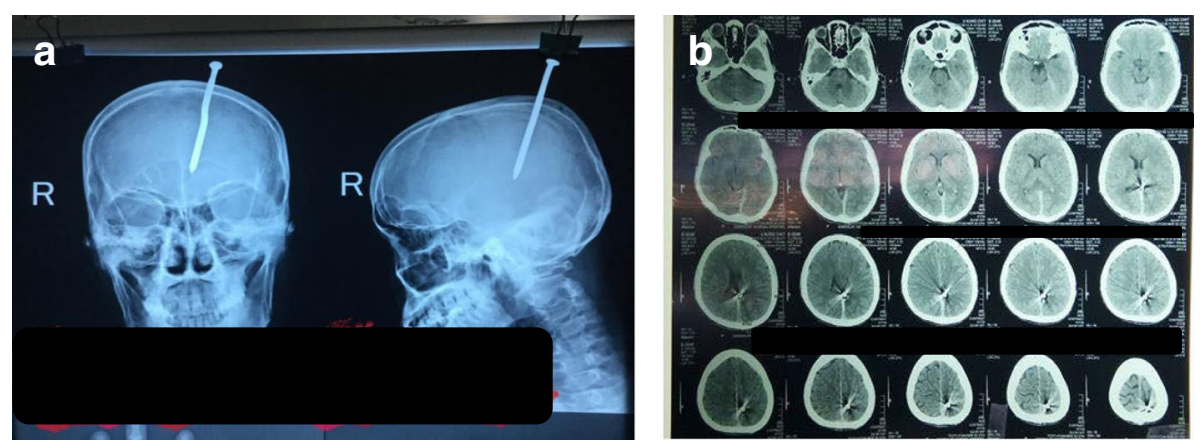

Fig 6. a X-ray views show the implanted nail. b CT of the same patient 

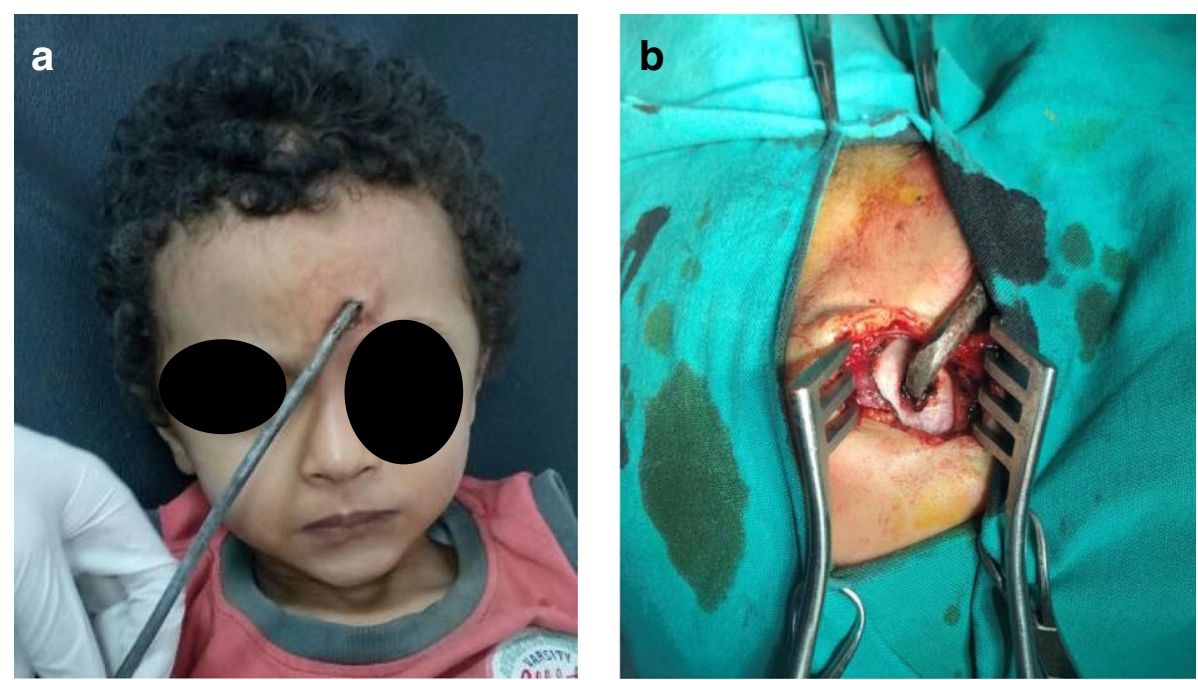

Fig. 7 A 4-year-old boy was presented to the emergency department with an iron rod stuck piercing his skull, and he was fully conscious with no neurological deficit. a The patient with an implanted iron rod. $\mathbf{b}$ The implanted iron rod stuck in OR

required prolonged hospital stay, mostly because of the need for prolonged postoperative rehabilitation. Of the 18 patients in this study, $15(83.3 \%)$ gained the ability for self-care and were discharged.

\section{Discussion}

The majority of our cases was in the second decade and during the fight which is consistent with Izci et al. [7]. TBI is classified according to the extent of brain injury into mild, moderate, or severe. A low Glasgow coma score (GCS) score at admission is usually correlated with severe
TBI, the outcome of which is variable from mild cases with complete recovery to major permanent disability or even death. Mild and moderate TBI may also cause a group of temporary or permanent physical, cognitive, emotional, and social problems $[8,9]$.

Optimum management of penetrating brain injury needs sufficient understanding of the mechanism and pathophysiology of injury. Computed tomography scanning considered as the neuroradiological modality of choice for penetrating brain injuries. Cerebral angiography is recommended in patients when penetrating brain injuries carry a high suspicion of vascular injury [10].
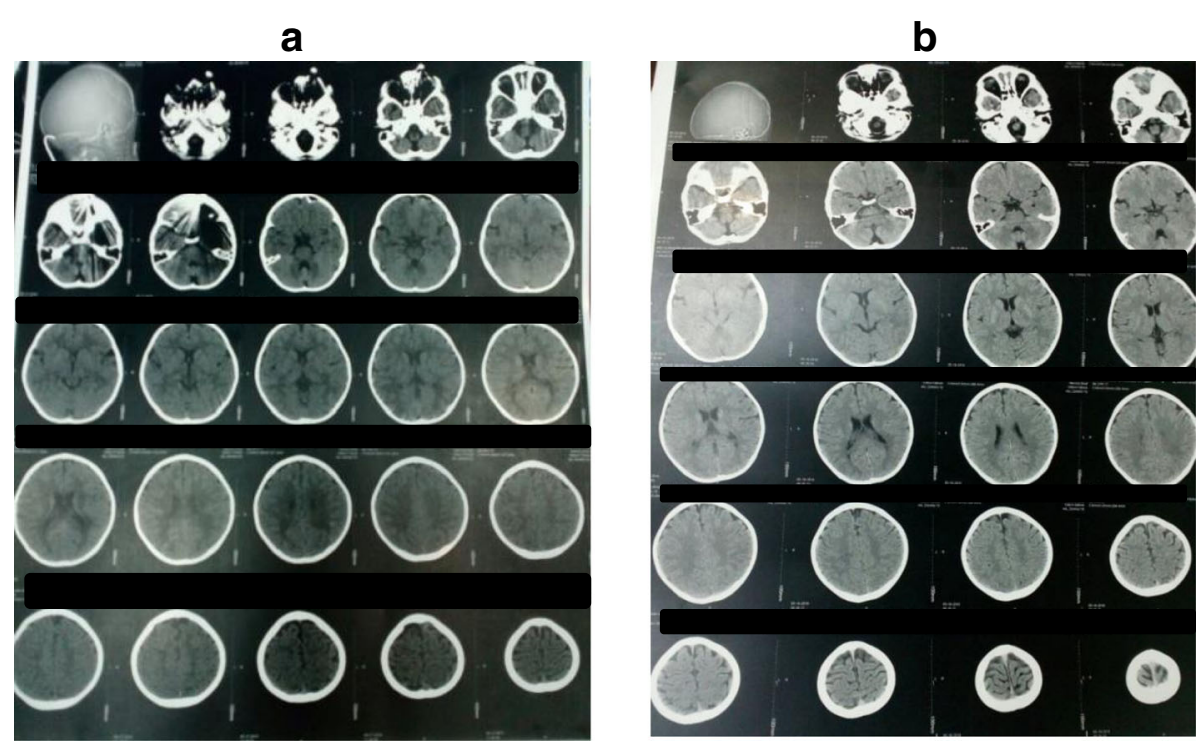

Fig. 8 a Preoperative and $\mathbf{b}$ postoperative $C T$ scans of the same patient 


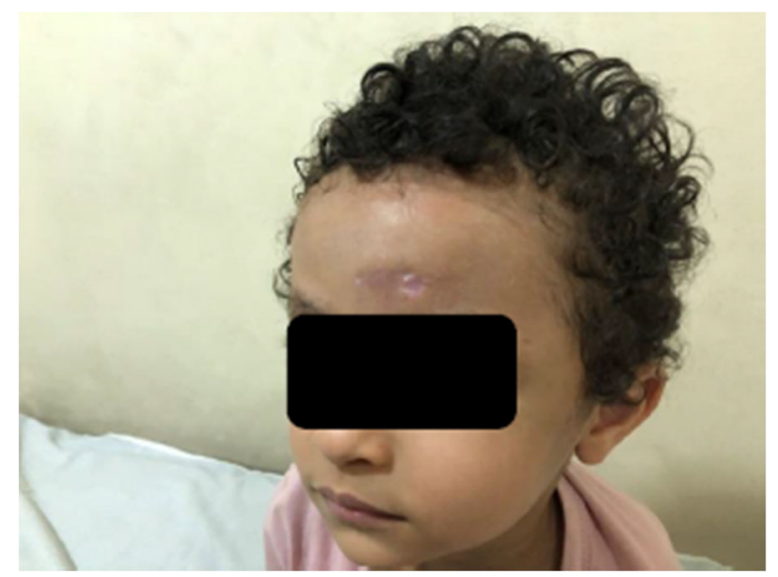

Fig. 9 Patient after 2 weeks follow-up

The recent trend now in management of penetrating brain injuries is toward a minimal invasive and a less aggressive surgical debridement of deeply seated bone and metal fragments. With a shift toward the conservative line by aggressive antibiotic prophylaxis to guard against intracranial infection and use of anticonvulsants drugs due to the high risk of post-traumatic in these patients. Surgery will be recommended in patients with cerebrospinal fluid (CSF) leaks those which do not close spontaneously or are refractory to CSF diversion through a ventricular or lumbar drain [10].

When there is a significant mass effect either in the form of necrotic brain tissue or intracranial hematoma, surgery should be performed. Necrotic brain tissues should be debrided and removal of safely accessible bone fragments should be done. Intracranial hematomas should be evacuated [11-13]. It was found that the routine surgical removal of bone fragments lodged deep in the brain in a far distance from the entry site especially in the eloquent areas of the brain is not recommended. Although theoretically the removal of these foreign bodies from the eloquent cortex may decrease the risk of posttraumatic convulsions, it has been found that it may worsen the outcomes with possibly higher morbidity, and a conservative approach in those cases has been recommended [11-14].

Surgical treatment should be performed within the first $12 \mathrm{~h}$ from the time of injury to decrease the risk of infectious complications [13, 15]. Surgical incision is preferred to be done in the site of injury and is related to the area that requires debridement. When an air sinus has been injured or violated in the route of the non-

\section{Sex}

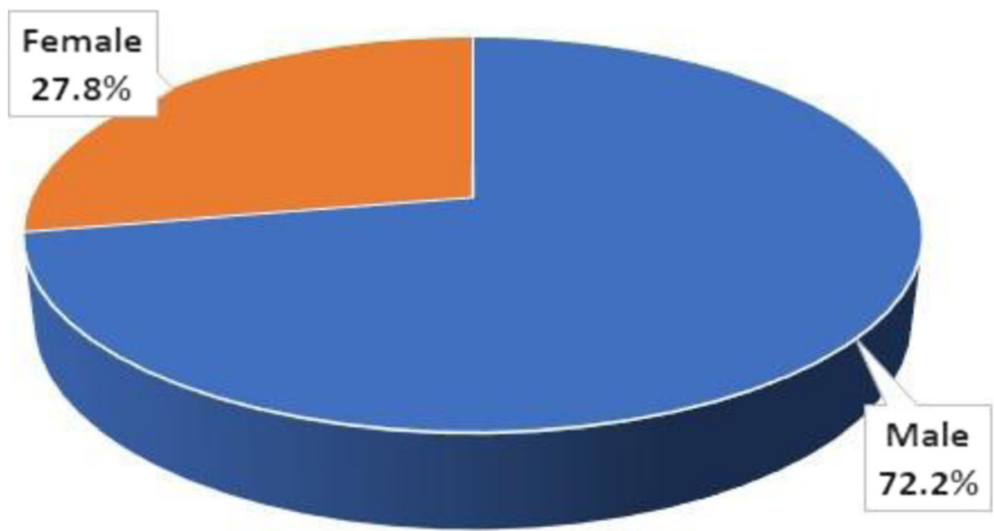

Fig. 10 Sex distribution of the study group 


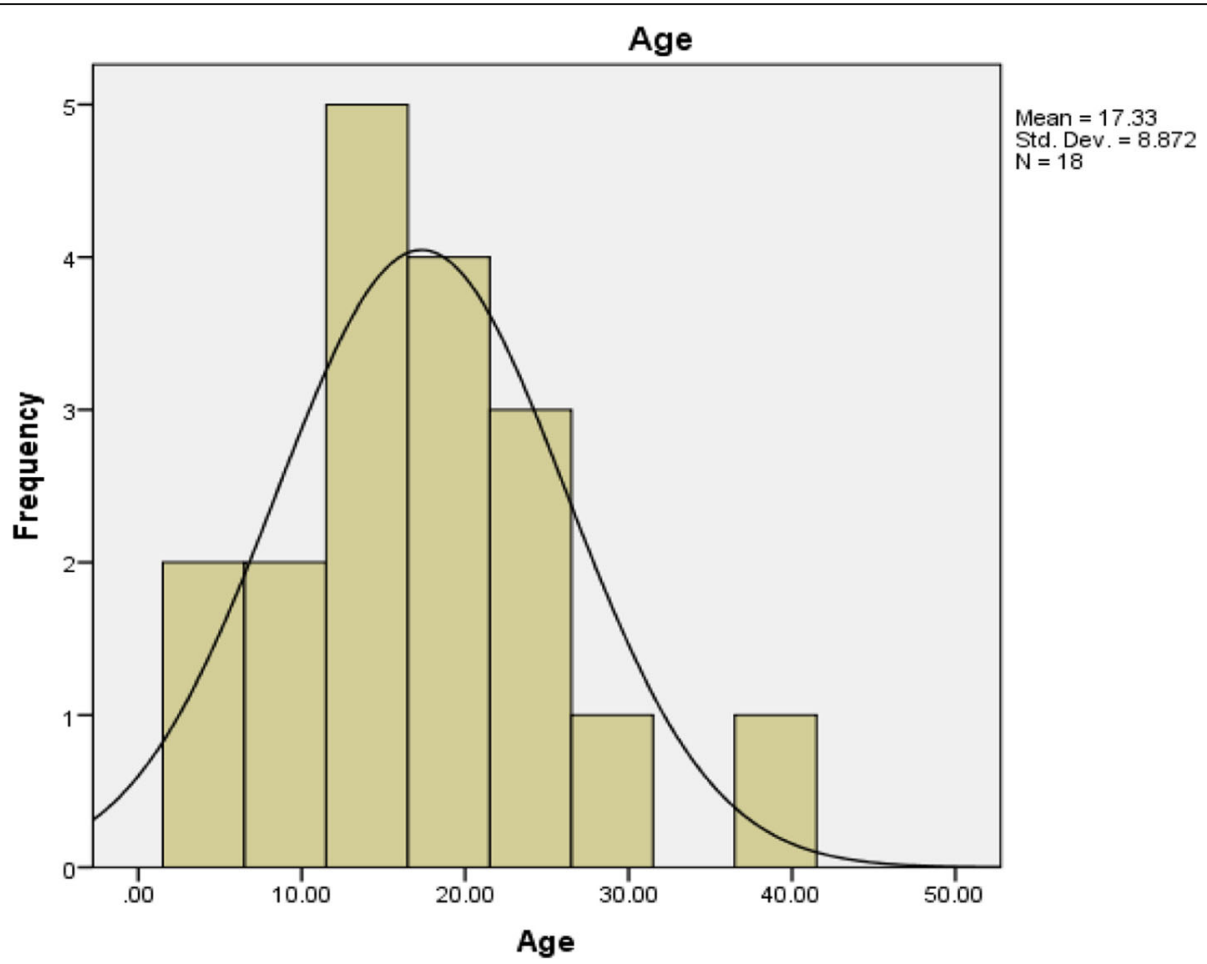

Fig. 11 Age distribution of the study group

missile, a water tight closure of the dura should be performed aiming to decrease the risk of abscess formation and CSF fistulas $[15,16]$.

Infectious complications after PBI are not uncommon, and they are associated with higher rates of morbidity and mortality, due to the contamination of foreign objects, hair, skin, and bone fragments which can be driven into the brain tissue along the pathway of the causative tool $[3,17,18]$. One case was reported with hydrocephalus which is the same in another study [19, 20,7].

The infectious complications which are the most common among the penetrating brain injuries include local wound infections, meningitis, ventriculitis, or cerebral abscess. The presence of cerebrospinal fluid leaks, air sinus wounds, transventricular injuries, or injuries crossing the midline will harbor the infectious complications $[3,17,18]$. Associated intraventricular

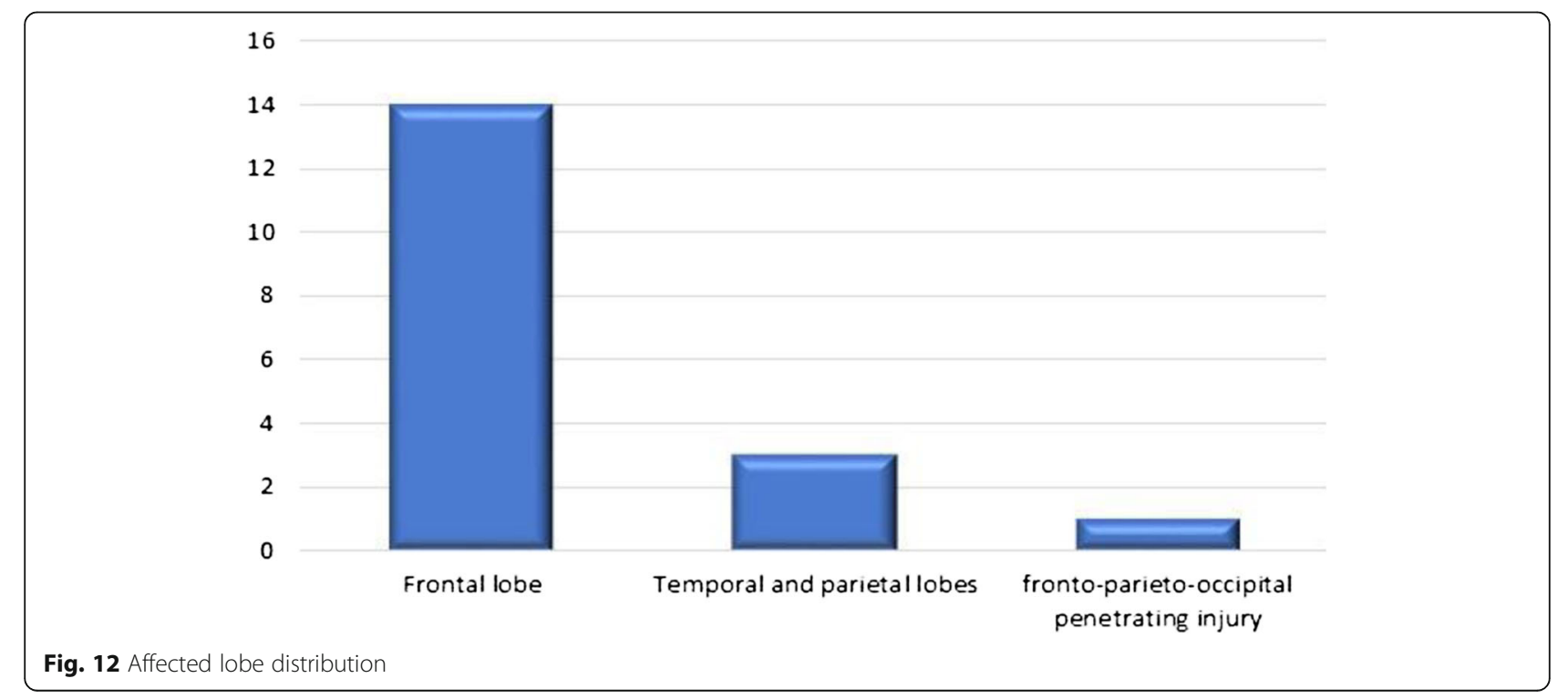


Table 1 Neurological data of the study group

\begin{tabular}{ll}
\hline Item & Value \\
\hline Site of injury & $14(77.78 \%)$ \\
Frontal & $3(16.67 \%)$ \\
Temporal and parietal & $1(5.56 \%)$ \\
Fronto-parieto-occipital & \\
Glasgow Coma Scale (GCS) & $9.17 \pm 3.47$ \\
Mean \pm SD & $9.5(3-15)$ \\
Median (range) & $5(27.78 \%)$ \\
GCS 3-7 & $13(72.22 \%)$ \\
GCS 8-15 & \\
Dural tear & $15(83.33 \%)$ \\
Simple repair & $3(16.67 \%)$ \\
Repaired with pericardial graft & $7(38.89 \%)$ \\
Intracerebral hematoma & $3(16.67 \%)$ \\
Ventricular injury &
\end{tabular}

hemorrhage was reported in $16.7 \%$ (three cases), while in another study was 55\% [7].

Another complication associated with craniocerebral penetrating brain injuries is posttraumatic epilepsy, which reflects the extent of brain damage and is positively correlated with com [21]. Incidence of seizures can be increased with the extent of brain damage and can reach $30-50 \%$ of patients suffering a PBI. In $10 \%$ of patients, seizures appeared early (first 7 days after the trauma), and $80 \%$ during the first 2 years, while about $10 \%$ may not have their first seizure until 5 or more years after injury. So the recent trend now is towards the recommended use of prophylactic anticonvulsants from the first week after penetrating brain injuries although the initial studies did not confirm the beneficial effect of the prophylactic anticonvulsants administration $[3,13$, 22, 23].

In our series, we observed postoperative seizures in six patients and anticonvulsants were administered. Anticonvulsants were discontinued if no seizures were reported after 2 years [24]. All individuals who suffered

Table 2 Complications of the study group

\begin{tabular}{ll}
\hline Complications & Number of patients \\
\hline Wound infection & $6(33.33 \%)$ \\
Posttraumatic seizures & $6(33.33 \%)$ \\
Neurological deficit & \\
Hemiparesis & $3(16.67 \%)$ \\
Monoparesis & $2(11 \%)$ \\
Intracranial hematoma & $3(16.67 \%)$ \\
Hydrocephalus & $1(5.56 \%)$ \\
CSF fistula & $0(0.0 \%)$ \\
\hline
\end{tabular}

Table 3 Causative tools

\begin{tabular}{ll}
\hline Tool & Number of patients \\
\hline Knives & $10(56 \%)$ \\
Nails & $4(22 \%)$ \\
Iron rods & $2(11 \%)$ \\
Key & $1(5.56 \%)$ \\
Hairpin & $1(5.56 \%)$ \\
\hline
\end{tabular}

brain damage received anticonvulsants as part of routine medical treatment $[1,25]$. On the other hand, all deaths occurred in our series were related to poor Glasgow coma score at the initial presentation and intraventricular hemorrhage, which correlates with another study [9], while no deaths occurred in another series [11].

Penetrating injury by a foreign body (rod stuck, knives, keys, axe) can result in a significant accumulation of intraventricular blood. This type of damage is associated with particularly poor prognosis. Penetrating brain injuries involving the ventricular system are more susceptible to intracranial sepsis because the disturbance of CSF flow dynamics makes them prone to CSF leakage and then infection. The highest mortality was in the posterior fossa and brain stem injuries while there was low mortality in frontal injuries $[4,7,9]$.

\section{Conclusion}

Strong antibiotics umbrella is crucial in PBI as it reduce the incidence of infection. With deeply seated fragments, no need for extraction. Prognosis in non-missile penetrating head injuries is generally favorable if the initial Glasgow coma score was normal. There is a strong correlation between the level of consciousness and intraventricular hemorrhage from one side and the outcome from the other side.

Moreover, CT brain is a cornerstone diagnostic tool in PBI. Further studies with higher number registry should be performed on penetrating brain injuries.

\section{Abbreviations}

CNS: Central nervous system; CSF: Cerebrospinal fluid; CT: Computed tomography; GCS: Glasgow coma score; ICU: Intensive care unit; PBI: Penetrating brain injuries; TBI: Traumatic brain injury

\section{Acknowledgements}

The authors would like to thank the whole members of Neurosurgery Department for allowing us to analyze traumatized patients' data for this study.

\section{Authors' contributions}

AS gave the idea of the study and collected the patients' data and postoperative follow-up of patients in the study. AK designed the study and analyzed the data. Both wrote with meticulous revision of the paper and approved the final version of the manuscript. 


\section{Availability of data and materials}

The datasets used and/or analyzed during the current study are available from the corresponding author on reasonable request.

\section{Ethics approval and consent to participate}

We had an approval from the local ethical committee concerning aspects of medical research. All cases included in this study had signed informed written consent to participate in this research and to publish the data before being included in the study. Informed written consent to participate in the study was provided by the parent(s) or legal guardian(s) for patients under the age of 18 (signed by the first-degree relative in non-fully conscious patients).

The ethical committee of the Faculty of Medicine, Sohag University, Egypt, approved this research prior to starting it, 68/2015 (reference email: emmedicine@sohag.edu.eg, reference phone number: +2-093-4573124).

\section{Consent for publication}

Written informed consent for publication of patients' data was obtained from the patient his/herself, or in the case of children under 16, their parent or legal guardian, or in case the patient is deceased, from the next of kin.

\section{Competing interests}

The authors declare that they have no competing interests (financial or nonfinancial).

Received: 22 November 2018 Accepted: 15 July 2019

Published online: 29 July 2019

\section{References}

1. Erdogan E, Gonul E, Seber N. Craniocerebral gunshot wounds. Neurosurgery Quarterly. 2002;12:1-18.

2. Kaufman HH, Makela ME, Lee KF, Haid RW Jr, Gildenberg PL. Gunshot wounds to the head: a perspective. Neurosurgery. 1986;18:689-95.

3. Esposito DP, Walker JP. Contemporary management of penetrating brain injury. Neurosurg Q. 2009:19:249-54.

4. Liebenberg WA, Demetriades AK, Hankins M, Hardwidge C, Hartzenberg BH. Penetrating civilian craniocerebral gunshot wounds: a protocol of delayed surgery. Neurosurgery. 2005;57(2):293-9 discussion 293-9.

5. Vivien B, Lamhaut L, Carli P. An unexpected intracranial blade. Prehosp Emerg Care. 2013;17(1):95-7.

6. Martins RS, Siqueira MG, Santos MT, Zanon-Collange N, Moraes OJ. Prognostic factors and treatment of penetrating gunshot wounds to the head. Surg Neurol. 2003;60(2):98-104 discussion 104.

7. Izci Y, Kayali H, Daneyemez M, Koksel T, Cerrahoglu K. The clinical, radiological and surgical characteristics of supratentorial penetrating craniocerebral injuries: a retrospective clinical study. Tohoku J Exp Med. 2003;201:39-46.

8. Hoge CW, McGurk D, Thomas JL, Cox AL, Engel CC, Castro CA. Mild traumatic brain injury in US soldiers returning from Iraq. N Engl Med J. 2008; 358:453-63.

9. Izci Y, Kayali H, Daneyemez M, Koksel T. I Comparison of clinical outcomes between anteroposterior and lateral penetrating craniocerebral wounds. Emerg Med J. 2005;22:409-10.

10. Kazim SF, Shamim MS, Tahir MZ, Enam SA, Waheed S. Management of penetrating brain injury. J Emerg Trauma Shock. 2011;4(3):395-402.

11. Chaudhri KA, Choudhury AR, al Moutaery KR, Cybulski GR. Penetrating craniocerebral shrapnel injuries during "Operation Desert Storm": early results of a conservative surgical treatment. Acta Neurochir (Wien). 1994;126:120-3.

12. Hammon WM. Analysis of 2187 consecutive penetrating wounds of the brain from Vietnam. J Neurosurg. 1971;34:127-31.

13. Salazar AM, Jabbari B, Vance SC, Grafman J, Amin D, Dillon JD. Epilepsy after penetrating head injury, I. Clinical correlates: a report of the Vietnam Head Injury Study. Neurology. 1985;35:1406-14.

14. Sonmez E, Borcek AO, Guven C, Hasturk AE. An iron rod stuck in the right motor cortex. Turk Neurosurg. 2012;22(6):772-4.

15. Helling TS, McNabney WK, Whittaker CK, Schultz CC, Watkins M. The role of early surgical intervention in civilian gunshot wounds to the head. J Trauma. 1992;32:398-400.
16. Hubschmann O, Shapiro K, Baden M, Shulman K. Craniocerebral gunshot injuries in civilian practice: prognostic criteria and surgical management experience with 82 cases. J Trauma. 1979;19:6-12.

17. Bauer M, Patzelt D. Intracranial stab injuries: case report and case study. Forensic Sci Int. 2002;129(2):122-7.

18. Gutiérrez-González R, Boto GR, Rivero-Garvía M, Pérez-Zamarrón A, Gómez G. Penetrating brain injury by drill bit. Clin Neurol Neurosurg. 2008;110:207-10.

19. Aarabi B, Taghipour M, Alibaii E, Kamgarpour A. Central nervous system infections after military missile head wounds. Neurosurgery. 1998:42:500-9.

20. Gonul E, Baysefer A, Kahraman S, Ciklatekerlioğlu O, Gezen F, Yayla O, Seber $\mathrm{N}$. Causes of infections and management results in penetrating craniocerebral injuries. Neurosurg Rev. 1997;20:177-81.

21. Caveness WF, Walker AE, Ascroft PB. Incidence of posttraumatic epilepsy in Korean veterans as compared with those from World War I and World War II. J Neurosurg. 1962;19:122-9.

22. Aarabi B, Taghipour M, Haghnegahdar A, Farokhi MR, Mobley L. Prognostic factors in the occurrence of posttraumatic epilepsy after penetrating head injury suffered during military service. Neurosurg Focus. 2000;8:e1.

23. Caporlingua A, Caporlingua F, Lenzi J. Good outcome after delayed surgery for orbitocranial non-missile penetrating brain injury. Asian J Neurosurg. 2016:11(3):309.

24. Weiss GH, Salazar AM, Vance SC, Grafman JH, Jabbari B. Predicting posttraumatic epilepsy in penetrating head injury. Arch Neurol. 1987; 43:771-3.

25. Rish BL, Dillon JD, Weiss GH. Mortality following penetrating craniocerebral injuries. J Neurosurg. 1983;59:775-80.

\section{Publisher's Note}

Springer Nature remains neutral with regard to jurisdictional claims in published maps and institutional affiliations.

\section{Submit your manuscript to a SpringerOpen ${ }^{\circ}$ journal and benefit from:}

- Convenient online submission

- Rigorous peer review

- Open access: articles freely available online

High visibility within the field

- Retaining the copyright to your article

Submit your next manuscript at $\boldsymbol{\nabla}$ springeropen.com 